\title{
The Impact of Earnings on the Pricing of Credit Default Swaps
}

\author{
Jeffrey L. Callen*, Joshua Livnat** and Dan Segal*
}

\begin{abstract}
This study evaluates the impact of earnings on firm credit risk as captured by Credit Default Swaps (CDS). We find that earnings (changes) are negatively correlated with one-year swap premia (changes) after controlling for equity returns but not with longer term premia (changes). We also find that earnings surprises are significantly correlated with one-year CDS premia changes in the short window surrounding preliminary earnings dates and that absolute earnings surprises are significantly correlated with absolute one-year CDS premia changes in the short window surrounding SEC filing dates. These results suggest that high earnings convey favorable information about the short-term default risk of firms but not about the long term default risk. We further document that accruals/cash flow information conveyed by SEC filings provides information about long-term credit risk. Furthermore, the empirical results are consistent with structural and hybrid model-driven implications of CDS pricing.

* Rotman School of Management

University of Toronto

105 St. George St.

Toronto Ontario

Canada M5S 3E6

e-mail Callen: callen @rotman.utoronto.ca

e-mail Segal: dsegal@rotman.utoronto.ca

** Stern School of Business

New York University

New York, NY

USA 10012

e-mail: jlivnat@stern.nyu.edu
\end{abstract}

JEL: G12, G14, M41

Keywords: Credit Default Swaps, Credit Risk, Earnings 


\title{
The Impact of Earnings on the Pricing of Credit Default Swaps
}

\begin{abstract}
This study evaluates the impact of earnings on firm credit risk as captured by Credit Default Swaps (CDS). We find that earnings (changes) are negatively correlated with one-year swap premia (changes) after controlling for equity returns but not with longer term premia (changes). We also find that earnings surprises are significantly correlated with one-year CDS premia changes in the short window surrounding preliminary earnings dates and that absolute earnings surprises are significantly correlated with absolute one-year CDS premia changes in the short window surrounding SEC filing dates. These results suggest that high earnings convey favorable information about the short-term default risk of firms but not about the long term default risk. We further document that accruals/cash flow information conveyed by SEC filings provides information about long-term credit risk. Furthermore, the empirical results are consistent with structural and hybrid model-driven implications of CDS pricing.
\end{abstract}




\section{Introduction}

There is voluminous evidence regarding the impact of earnings and accounting information generally on equity investors. By contrast, very little is known about how earnings and other accounting information impact on other stakeholders of the firm. This lacuna is especially troubling since from the perspective of the FASB's conceptual framework, corporate financial reports are general purpose statements that serve as potential inputs into the decision making calculus of all of the firm's stakeholders. The paucity of evidence regarding the impact of accounting information generally and earnings in particular on non-equity capital markets likely stems from the limited liquidity of these markets. Corporate bonds, for example, do not trade very often by comparison to equities, and short-term changes in published bond prices are often insensitive to small changes in the default risk, which is precisely what earnings and balance sheet information (such as leverage and liquidity) can be most useful in measuring. Proxies for bond risk such as credit ratings are also very sticky so that impact of accounting information on short-window changes in bond risk is equally difficult to ascertain from ratings data.

The purpose of this paper is to evaluate the impact of earnings on short- and longwindow changes in firm credit risk, as captured by Credit Default Swaps (CDS). Credit risk is of concern to many of the firm's stakeholders including stockholders, bondholders, bank lenders, customers, employees and regulators. In particular, we investigate whether earnings and other balance sheet information (using preliminary earnings announcements and SEC filings) impact on the price of credit risk as reflected in CDS premia (spreads). 
Our results show that the levels of one-year, but not five- or ten-year, CDS premia are inversely related to quarterly earnings, implying that higher profits signify lower default risk in the short-run but not the long-run. We also show that changes in one and five-year CDS premia over the quarter are inversely related to earnings changes over the quarter, and that short-window one-year CDS premia changes around preliminary earnings announcements are inversely related to earnings surprises, further indicating that higher earnings are interpreted by market participants as evidence of lower short-run default risk. Absolute values of short-window changes in one-year CDS premia around SEC filing dates are found to be associated with the absolute value of earnings surprises, indicating that the additional information in SEC filings are used by market participants in reinterpreting the effects of preliminary earnings surprises on CDS premia. Finally, we show that the changes in ten-year CDS premia around SEC filing dates are positively (negatively) associated with the accruals (cash flows) components of earnings. This finding is consistent with the notion that higher accruals (cash flows) are indicative of lower (higher) quality earnings, and therefore of higher (lower) risk of default. All of these enumerated results hold even controlling for the earnings information contained in equity returns

In what follows, Section 2 briefly describes the CDS market. Section 3 develops the hypotheses to be tested. Section 4 describes the sample. Section 5 presents the empirical analysis. Section 6 concludes.

\section{The CDS Market}


Financial innovation has led to the creation of credit derivatives to manage credit risk. Surveys indicate that the outstanding notional amount of credit derivatives reached $\$ 8.42$ trillion by the end of 2004 , more than double the size of the total equity derivatives market of $\$ 4.15$ trillion at the same date. The growth in credit derivatives can be attributed to four market participants. The largest group in the credit derivatives market is comprised of large commercial banks, who are net buyers of credit derivative protection. ${ }^{1}$ Traditionally, a bank's business involves credit risk if only because of corporate loan originations. Unlike securitizations, credit derivatives offer banks an attractive way to transfer credit risk without removing the loans from their balance sheets and without directly involving borrowers. In addition, credit derivative contracts allow banks to diversify their portfolios, which often are concentrated in certain industries or geographic areas. Insurance companies comprise the second largest group. They are increasingly becoming dominant participants in the credit derivative market as they attempt to enhance investment yields. Globally, insurance companies have net sold positions in the credit derivative market since they primarily sell insurance protection. Other participants include financial guarantors, who are also net protection sellers, and global hedge funds.

The most common credit derivative is the single-name credit default swap (CDS). The CDS market has grown rapidly in no small part due to the standardization of CDS contract definitions in 1998 by the International Swaps and Derivatives Association, since amended a number of times. A CDS is an over-the-counter contract that provides protection against credit risk. Not unlike a common insurance contract, the protection

\footnotetext{
${ }^{1}$ See Minton et al. (2006).
} 
buyer pays a fixed premium, the spread, to the protection seller for a period of time. ${ }^{2}$ If a certain pre-specified credit event occurs to a specific company, called the reference entity, the protection seller pays compensation to the protection buyer. A credit event can be the bankruptcy of the reference entity or a bond default by the reference entity. If the protection buyer does not hold the reference bond, then compensation is in the form of a lump sum payment equal to the difference between the value of the reference entity's bond and its face value. Alternatively, if the protection buyer holds the bond, the compensation can be either in the form of a lump-sum payment or the protection buyer can deliver the reference entity's bond to the protection seller for its face value. If no credit event occurs during the term of the swap, the protection buyer continues to pay the swap premia until maturity.

The premium paid by the protection buyer to the seller is quoted in basis points per annum of the contract’s notional value--typically $\$ 10$ million--and is usually paid quarterly. For example, suppose that the CDS spread for a five-year \$10 million contract on the Siemmens Corporation is 200 basis points and the credit event is defined to be default of Siemmens' bonds. This means that the protection buyer pays \$50,000 (two percent of $\$ 10 \mathrm{M})$ per quarter to the protection seller for 5 years or until Siemmens defaults on its bonds. In the event that Siemmens defaults on its bonds, the protection buyer, in turn, has the right to sell Siemmens' bonds to the protection seller for their face value of $\$ 10$ million. Maturities typically range from one to ten years, with the five-year maturity being the most common.

\footnotetext{
${ }^{2}$ Unlike standard insurance, it is not necessary to hold an insured asset (e.g., the underlying bond or loan) in order to claim 'compensation' with a CDS. Speculators can take long (short) positions in credit risk by selling (buying) protection without having to trade the cash instrument.
} 
Although the credit risk profile of a CDS is similar to that of a corporate bond of the reference entity, CDS premia offer many advantages over corporate bond yield spreads for analyzing the pricing determinants of credit risk. ${ }^{3}$ First, as shown by Elton et al. (2001), as much as 85 per cent of corporate bond yield spreads can be explained as a reward for bearing systematic risk unrelated to default. Second, unlike CDS spreads that reflect pure credit risk, bond yields are a function of many factors, such as interest rate risk. As a consequence, small changes in profitability or leverage that affect default risk are unlikely to cause significant enough changes in bond yield spreads by comparison to CDS premia. Third, unlike bond yield spreads, no benchmark risk-free rate need be specified for CDS premia. Fourth, CDS premia are not distorted by embedded options features such as calls and covenants as are bond yields. ${ }^{4}$

In addition, there are a number of institutional differences in the market for bonds and CDS which contributed to the phenomenal growth in CDS trading. First, a CDS does not require initial funding, which allows for leveraged positions. Second, a CDS transaction can be entered into even if a cash bond of the reference entity at a particular maturity is not available. Finally, by entering a CDS contract as a protection seller, an investor can easily create a short position in the reference entity’s credit.

Although the CDS premium is related to credit ratings by rating agencies, there is quite a variation in CDS spreads that are observed for firms with a given credit rating. Unlike credit ratings which tend to be "sticky" and are a function of many factors other

\footnotetext{
${ }^{3}$ The corporate bond yield spread is usually defined as the yield differential between the corporate bond yield and a AAA or US Treasury Bond of similar maturity.

${ }^{4}$ Other disadvantages of bond yield spreads include tax differentials in bond pricing and evidence that the bond market lags the CDS market in incorporating timely credit risk information. On the latter issue, see Blanco et al. (2005) and Zhu (2004).
} 
than credit risk, CDS rates tend to lead changes to the credit profile of the reference entity and reflect only the credit risk of the reference entity. ${ }^{5}$

Overall, the superiority of CDS prices over bond yield spreads and credit ratings allows for a more rigorous empirical analysis of the relation between financial information and credit risk.

\section{Literature and Hypotheses Development}

The finance literature proposes two model types to explain the pricing of credit derivates, structural models and reduced form models. Structural models are based upon the seminal paper by Merton (1974). The structural modeling approach links the prices of credit risky instruments directly to the economic determinants of financial distress and of loss given default, conditional on knowing the firm's asset value process. ${ }^{6}$ These models imply that the main determinants of the likelihood and severity of default are financial leverage, the value and volatility of the firm's assets, and the risk-free rate of interest. Despite the intuitive appeal of structural models and their strong theoretical underpinnings, the direct use of structural models to price credit derivatives typically yields poor results, probably because the parameters of the firm's asset value process are difficult to observe. $^{7}$

Reduced form models such as those by Das (1995), Das and Sundaram (1998) and Hull and White (2000a, 2000b) do a better job at directly pricing credit derivatives. The

\footnotetext{
${ }^{5}$ See Hull et al. (2004) regarding the relationship between credit rating changes, CDS premia and bond prices. A number of paper examine the impact of credit rating changes, as measures of default risk changes, on equity returns including Dichev and Piotroski (2001), Vassalou and Xing (2003), and Jorion and Zhang (2005).

${ }^{6}$ See for example Black and Cox (1976), Leland and Toft (1996), Longstaff and Schwartz (1995) and Collin-Dufresne and Goldstein (2001)

${ }^{7}$ See most recently Eom, Helwege and Huang (2004).
} 
firm's asset value process is abandoned. Instead, reduced form models exogenously postulate the dynamics of default probabilities. However, reduced form models tend to be "black boxes" that are silent about the underlying determinants of the price of credit risky instruments. Somewhat better economic insights are provided by hybrid models that feature both structural and reduced form elements, such as those by Duffie and Lando (2001) and Buhler and Thabe (2006)

Rather then trying to directly price credit derivatives using structural models, we follow the more recent regression approach of Collin-Dufresne, Goldstein, and Martin (2001) (CGM). ${ }^{8}$ They "borrow" from the structural approach to identify the theoretical determinants of credit risk. These determinants are then used as independent variables to explain corporate credit spreads, rather than inputs to a particular structural model. Although CGM themselves estimate bond yield spreads, ${ }^{9}$ a similar approach using CDS premia is taken by Cossin and Hricko (2001), Aunon-Nerin et al (2002), Abid and Naifar (2005), and Ericsson et al (2005).

Based on a sample of 393 multi-country CDS transactions, Cossin and Hricko (2001) and Aunon-Nerin et al. (2002) estimate levels regressions to examine whether leverage, credit ratings, US and other national risk-free interest rates, the slope of the (US) yield curve, stock prices, time to maturity, stock volatility, market capitalization (liquidity), and country stock index returns explain CDS spreads. Depending upon the specific levels regression ${ }^{10}$, they find that a number of these factors significantly explain

\footnotetext{
${ }^{8}$ One can think of the linear regressions in this paper as a first-order approximation to a structural model.

${ }^{9}$ The relationship between bond yield spreads and CDS premia is a topic of active research in the finance literature. See, for example, Blanco et al. (2005) and Longstaff et al. (2005). Another related active area of research is the relationship between equity returns and credit risk as reflected in credit derivative prices. See most recently Chan-Lau (2006).

${ }^{10}$ Interestingly, they do not regress CDS premia on all of the explanatory variables simultaneously, possibly because of multicollinearity.
} 
CDS spreads in the hypothesized direction, most crucially credit ratings, leverage, stock prices and the slope of the yield curve.

Using a sample of 207 multi-country CDS transactions, Abid and Naifar (2005) analyze the relation between credit swap rates and such determinants as credit rating, time to maturity, the riskless interest rate, the slope of the yield curve, and the volatility of equities. In a series of (essentially bivariate) levels regressions involving credit ratings and one other determinant, they find that most of the determinants that they investigate are significant.

Erricson et al. (2005) employ a far more comprehensive sample of approximately 10,000 daily bid and offer quotes on US corporations with an approximate five-year maturity to analyze the relation between credit spreads and its determinants. Various (panel data and time series) levels and difference regressions are estimated with explanatory variables including leverage, long and short term risk-free interest rates, the slope of the yield curve, the smirk slope, stock volatility, and the S\&P index return. Separate regressions are run for high and low rating firms and for bid and offer quotes. Not surprisingly they find that the levels regressions are far more significant than the difference regressions. Overall, they find that leverage, stock volatility and the interest rate are significant and of the hypothesized sign.

It bears emphasizing that none of these empirical papers investigate the impact of earnings on credit swap spreads. One can offer two reasons as to why the literature has failed until now to incorporate earnings as a determinant of credit derivative pricing. First, earnings per se are not a direct determinant of premia in "pure" structural and reduced form credit derivative pricing models. Second, earnings may be subsumed by 
equity returns which are in turn a function of earnings (Ball and Brown (1968)). Neither reason is compelling. In structural models, the price of credit derivates is a function of the likelihood and severity of financial distress (the credit event), and the more profitable is the firm, the less likely it is to suffer from financial distress. Furthermore, earnings play a role (as do other types of accounting information) in estimating the true asset dynamics and the default probability of the firm in hybrid models where there is imperfect information about the asset dynamics. ${ }^{11}$ Moreover, the extent to which earnings are subsumed by equity returns in the pricing of credit derivatives can be dealt with by controlling for equity returns in the regressions.

Increased profitability of the reference entity, as measured by current accounting earnings, should reduce its credit risk since, with increased profitability, the reference entity is less likely to go bankrupt or to default on a bond payment. Furthermore, the shorter the maturity of the CDS, the more likely is an increase (decrease) in profitability to provide positive (negative) information about the reference entity's ability to repay bondholders within the maturity period. Contrariwise, longer term maturities are less likely to be affected by current earnings since what matters for longer maturities is the firms' ability to pay bondholders in the long run. These considerations yield the following set of hypotheses stated in the alternative:

H1: The quarter-end CDS premium is inversely related to the reference entities' quarterly earnings. The relation between the CDS premium and the reference entities' earnings is a decreasing function of CDS maturity.

\footnotetext{
${ }^{11}$ See Duffie and Lando (2001) and Buhler and Thabe (2006). These models are sufficiently abstract that they rationalize the use of accounting information generally, in contrast to earnings per se.
} 
H2: The percent change in the CDS premium over the quarter is inversely related to the change in the reference entities' quarterly earnings. The relation between the percent change in the CDS premium and the change in the reference entities' earnings over the quarter is a decreasing function of CDS maturity.

H3: The percent change in the CDS premium in the short window centered on the preliminary earnings announcement is inversely related to the reference entities' earnings surprise. The relation between the percent change in the CDS premium around the preliminary earnings announcement and the reference entities' earnings surprise is a decreasing function of CDS maturity.

All three hypotheses are similar but expressed at different levels of timing aggregation. H1 refers to the relation between the level of the CDS premium and the level of the reference entity's quarterly earnings. $\mathrm{H} 2$ refers to the relation between the change in the CDS premium and the change in the reference entity's earnings over the quarter. H3 refers to the short-window relation between the CDS premium and preliminary earnings announcements.

The relationship between the price of credit risk and SEC filings announcements is bound to be more complex than that of the price of credit risk and preliminary earnings announcements. First, since SEC filings typically come after the preliminary earnings announcement, it is unclear whether the SEC filing represents good or bad news a priori. Rather, as far as the earnings number is concerned, the SEC filing potentially provides 
new information that revises the information content of the preliminary earnings. One possible reason for the reinterpretation of the preliminary earnings number is the additional information, if any, conveyed by the breakdown of earnings into cash flows and accruals. Second, the SEC filing potentially provides new information about the firms' assets and liabilities that may be more germane for evaluating credit risk than the information contained in the income statement. Again, we should expect that the information contained in SEC filings should be more relevant for evaluating the firm's more immediate credit risk than longer term credit risk. These considerations lead to our next two hypotheses:

H4: The absolute value of the percent change in the CDS premium in the short window centered on the SEC filing date is inversely related to the reference entities' absolute earnings surprise. The relation between the percent change in CDS spread around the SEC filing and the reference entities' absolute earnings surprise is a decreasing function of CDS maturity.

H5: The percent change in the CDS premium in the short window centered on the SEC filing is inversely (positively) related to the reference entities' cash flow (accruals). The relation between the change in the CDS spread around the SEC filing date and the reference entities' cash flow/accruals is a decreasing function of CDS maturity.

The empirical testing of the hypotheses in this paper is based primarily upon cross-sectional analyses. Thus, it is crucial to control for factors other than earnings that 
are known to affect swap spreads. The structural modeling approach links the prices of credit risky instruments directly to the economic determinants of financial distress and to the severity of loss given default. These determinants can be divided into (i) factors that are specific to the reference entity and (ii) macroeconomic factors. These models imply that the main firm-level determinants of the likelihood and severity of default are financial leverage, the value of the firm's assets, and the volatility of those assets. More specifically, the higher the leverage, the lower the asset value and the more volatile the assets of the reference entity, the higher is the probability of a credit event and so the higher is the swap premium. In addition, since ratings provide a noisy measure of credit risk, we control for credit ratings. We expect that the lower the credit rating, the higher is the swap premium. Furthermore, since the equity market may lead the CDS market in incorporating earnings, we also control for firm level equity returns.

The model-driven macroeconomic factors include the riskless rate of interest and the slope of the yield curve (as proxied by the difference between the riskless long-term and short-term interest rates). Intuitively, a higher rate of interest increases the drift rate for the firm's assets, thereby increasing the firm's wealth and making bankruptcy less likely. The slope of the yield curve controls for market expectations about future interest rate changes. Since the probability of default is likely dependent upon on the business environment, we also control for the information about future business conditions contained in aggregate equity returns. Therefore, we expect to find that the higher the risk-free rate, the greater the yield curve slope and the higher aggregate equity returns, the smaller is the swap premium. 


\section{Data}

The CDS data for 2002 through 2004 are provided by Lombard Risk. ${ }^{12}$ The data include sporadic CDS premia quotes in 2002, and daily mid-market mean CDS premia obtained from market makers in 2003 and 2004. In addition to the CDS premia, the data contain information about the maturity of the CDS, the currency in which it is denominated, reference firm identifiers (primarily ticker symbol) and various additional contract characteristics. ${ }^{13}$ Given that daily information is available from 2003, we restrict the CDS data to 2003 and 2004 (2,280,891 daily observations of the various CDS contracts for 786 firms).

Using the Preliminary Compustat database available to us through Charter Oak (and now available also on WRDS), we identify for each firm on Compustat the quarterly preliminary earnings release date and the financial information that was actually disclosed to market participants in the quarterly preliminary earnings announcements (e.g., operating cash flows) of 2003 and 2004. In addition, we obtain SEC filing dates for our sample firms from S\&P's Compustat (but not through the regular Compustat database).

Merging the two datasets using ticker symbols, and requiring CDS data around the preliminary earnings release date or the financial statement filing date, results in a sample of $476(2,211)$ firms (firm-quarters) and 26,021 CDS contracts. ${ }^{14}$ We then categorize the CDS contracts into one-year, five-year and ten- year maturities, in order to

\footnotetext{
${ }^{12}$ http://www.lombardrisk.com/

${ }^{13}$ The CDS contract data include maturity, seniority rank, currency, recoverability clauses, restructuring clauses and other factors. For example, on Nov. 30, 2004, the data include quotes on 16 CDS contracts of Bristol Myers Sqibb (ticker = BMY), the reference firm. These contracts differ in their maturity, recoverability clause, restructuring clause, and currency.

${ }^{14}$ The matching is done by using the historical ticker symbols available to us through the Charter Oak Point In Time database.
} 
investigate whether the impact of the financial information on CDS premia depends on the maturity of the contract. In addition, we require that the sample CDS contracts have similar characteristics other than maturities. Specifically, all CDS contracts in our sample are dominated in US dollars, classified as senior, and have identical recoverability and restructuring clauses. These restrictions reduce the sample to 4,143 CDS contracts $(1,214$, 1,596 and 1,333 for one-year, five-year, and ten-year maturities, respectively), and 1,634 firm-quarters (401 firms).

Stock returns and financial information for the sample firms are obtained from CRSP and Compustat, respectively.

Table 1 presents descriptive statistics for our sample observations. The firms covered in the database are large; the mean (median) firm has a market value of 14.366 (5.98) billion dollars. Thus, the results reported in this study are likely not generalizable to smaller firms. The percentage change of the CDS premium in the 3-day window centered on the preliminary earnings announcement date, CDS_PRL, has a mean (median) of $-0.002(0.000)$, or $-0.2 \%$ of the CDS premium at the beginning of the window. Similarly, the percentage change of the CDS premium in the 3-day window around the SEC filing has a mean of $0.5 \%$ and a median of $0.0 \%$. The percentage change in the CDS premium from one day after the SEC filing date of the previous quarter through one day after the SEC filing date of the current quarter, CDS_QTR, has a mean (median) of $-6.3 \%$ (-8\%), implying that CDS premia tend to decrease with the additional information learned throughout the quarter. The log of the CDS premium on the first day after the financial statement filing date, CDS_PRM, has an average (median) value of 3.99 (3.86) basis points, and varies between 2.1 and 6.8 basis points. 
(Insert Table 1 about here)

The mean quarterly return on assets (ROA), which is income before extraordinary items and discontinued operations scaled by total assets at the end of the quarter, is $1.3 \%$, which is reasonable considering the large firm bias in the sample. The change in ROA from the previous quarter has a mean (median) of 0.001 (0.001), indicating that most firms had positive earnings growth, which is consistent with the negative percentage change in the mean CDS premium over the quarter. Leverage, estimated as total debt divided by total assets at quarter end, has a mean (median) of $0.302(0.280)$. The change in leverage over the quarter has a mean of 0.002 and a median of 0.000 , suggesting a slight increase in leverage. The quarterly net operating cash flow (accrual) scaled by total assets at the previous quarter-end has a mean of $3.7 \%(-2.5 \%)$, which is in line with prior studies. As indicated by the Charter Oak database, about 37\% of the firms in our sample reported (net) operating cash flows in the preliminary earnings announcement. The S\&P senior debt rating for the sample observations (RATE) shows considerable variation with ratings of AAA (code 2) through CC (Code 23). RSUE is the rank (0 is the lowest rank and 9 is the highest) of the standardized earnings surprise (SUE). SUE is calculated from the Compustat quarterly database as preliminary EPS minus expected EPS, where the latter is computed from a seasonal random walk model with a drift scaled by the standard deviation of the forecast errors of the model. SUE is estimated for each quarter t, using all observations in quarters t-8 through t-1. The ranking of the earnings surprise is with reference to all firms in Compustat. The table shows that the earnings surprises of our sample firms are distributed evenly from the most negative surprise (lowest rank) to the most positive surprise (highest rank). The other variables that are important in determining CDS premia (the volatility of returns, 
the interest rate slope, and the return on the S\&P 500 Index) show considerable variation as well during our sample period.

\section{Empirical Results}

To test our hypotheses, we use all sample observations with maturities of one, five and ten years. Our tests involve regression analysis where the dependent variables are levels or changes in CDS premia and the independent variables are earnings, other model-driven and control variables specified above that are potentially important in explaining CDS premia. To control for different maturities, we interact all of the independent variables with two dummy variables, D5 (D10), that equal " 1 " if the maturity is five (ten) years. To control for firm and time effects and to reduce potential multicollinearity in the pooled regression, we use demeaned independent variables and allow for firm and year fixed effects in our analyses. The tables below report the estimated coefficients in three columns: the base case with no interaction terms corresponds to the one year maturity CDS contract (CDS_1), the estimated coefficients of the interactive terms with D5 (CDS_5), and the estimated coefficients of the interactive terms with D10 (CDS_10). Thus, the table coefficients for the columns headed CDS_5 and CDS_10 measure the incremental association of the variable with CDS premia beyond that of the one-year maturity. We also report at the bottom of the tables, certain tests of significance involving the sum of the tabulated coefficients of CDS_1 and CDS_5 and of CDS_1 and CDS_10.

The levels analysis (Hypothesis H1) is described in Table 2. CDS premia one day after the SEC filing date are regressed on the reference entity's normalized quarterly 
earnings (ROA), financial leverage (LEV), size (SIZE), the interest rate (INT), the return on the S\&P 500 index (S\&P), and firm return volatility (SDRET). The results strongly confirm H1. The spread is significantly and inversely related to earnings ( $\mathrm{p}=0.019$, twotailed) for the one-year maturity consistent with increased profitability, as expressed by earnings, reducing the price of short-term credit risk. By contrast, the longer CDS maturities have significantly positive incremental associations with earnings, indicating that earnings are likely to have less of an impact on CDS premium of mid-term and longterm maturities. Indeed, the tests at the bottom of the table indicate that ROA has an insignificant association with the 5-year ( $\mathrm{p}=0.765$, two-tailed), and 10-year ( $\mathrm{p}=0.124$, two-tailed) CDS premia.

\section{(Insert Table 2 about here)}

Table 2 also reveals that CDS premia are positively and significantly $(\mathrm{p}=0.000$, two-tailed) associated with the firm's leverage for the one-year maturity, and that these associations are lower for the five- and ten-year maturities as indicated by the negative coefficient on the leverage interaction terms. Thus, leverage levels affect CDS premiums, but more so for short-term maturities than mid-term or long-term maturities. As reported at the bottom of Table 2, the total effect of leverage on CDS premia for maturities of five and ten years are positive and significant $(\mathrm{p}=0.000$, two-tailed $)$, and there is a monotonically declining relationship between the effect of leverage on CDS premia and CDS maturity.

Table 2 shows that the coefficient estimates of the remaining variables conform to expectations. The premium increases significantly ( $\mathrm{p}=0.000$, two-tailed) with firm volatility, for the one-year maturity, but the association is attenuated for longer 
maturities. The premium is negatively and significantly $(\mathrm{p}=0.000$, two-tailed $)$ associated with size for the one-year maturity, with monotonically declining associations for the longer maturities. The interest rate is negatively and significantly $(\mathrm{p}=0.000$, two-tailed) associated with CDS premia for the one-year maturity, and with monotonically declining associations for longer maturities. The S\&P 500 return during the firm’s fiscal quarter is not significantly associated with CDS premia. ${ }^{15}$ The credit rating is not used as a control variable in this regression because it is highly correlated with size and leverage (correlations exceed 80\%). Substituting the credit rating for size and leverage, yields (untabulated) a significantly negative coefficient estimate for the credit rating ( $\mathrm{p}=0.000$, two-tailed), so that the higher the credit rating the lower is the CDS premium, and qualitatively similar results for the other estimated coefficients. ${ }^{16}$

Overall, the results in Table 2 are consistent with Hypothesis 1. Earnings are significantly and inversely related to one-year maturity CDS premia but not with 5 and 10 year CDS premia. The lack of significance for the longer maturities likely reflects the fact that short-term earnings do not provide sufficient information about long-term default probabilities and/or default losses. Furthermore, the results are consistent with the predictions of the structural models regarding the other determinants of CDS pricing.

Hypothesis $\mathrm{H} 2$ regarding quarterly changes in CDS premia is tested in Table 3. The dependent variable is the percentage change of the premium as computed from one day after the prior quarter's SEC filing date to one day after the current quarter's SEC filing date. This window is chosen because all quarterly financial statement information

\footnotetext{
${ }^{15}$ Similar results obtain if we replace the contemporaneous quarter S\&P return with the prior quarter S\&P return.

${ }^{16}$ Using longer term rates instead of the (annualized) 3-month rate yields qualitatively similar results. It proved impossible to control for the slope of the yield curve (SLOPE) because INT and SLOPE are too highly correlated.
} 
becomes available to the market on the SEC filing date. The independent variables in Table 3 are the quarterly changes in the independent variables of the levels analysis (Table 2) including one additional control variable, namely, the change in the credit rating. The results in Table 3 are consistent with H2. The change in the premium is inversely and significantly ( $\mathrm{p}=0.000$, two-tailed) related to the change in earnings (DEL_ROA) for the one-year CDS, with monotonically declining associations for the longer maturities. At the bottom of the table, we report that the change in earnings is inversely and statistically significant for the 5-year CDS (significance level of 0.006), and is insignificantly different from zero for the 10-year CDS. This is consistent with quarterly earnings changes affecting short and medium term credit risk, but not long-term credit risk.

\section{(Insert Table 3 about here)}

Surprisingly, Table 3 also shows that quarterly changes in leverage have no significant association with CDS premium changes for the one- and five-year maturities, but are positively and significantly ( $\mathrm{p}=0.049$, two-tailed) associated with the premium changes for the ten-year CDS. This implies that changes in leverage are incrementally more informative (beyond earnings) about the default risk of long-term maturities but not short-term or even medium-term maturities.

The premium also increases significantly ( $\mathrm{p}=0.059$, two-tailed) with increases in firm volatility and with changes in the economic environment as captured by the return on the S\&P 500 Index during the firm's fiscal quarter $(\mathrm{p}=0.000$, two-tailed $)$ for the oneyear CDS. The spread decreases significantly with increases in the interest rate $(p=0.000$, two-tailed) and with firm size ( $p=0.006$, two-tailed) for the one-year maturity. Since firm 
size is measured by market value, the latter result also indicates that equity returns do not swamp earnings changes as an explanatory variable of changes in the CDS premium. In an untabulated sensitivity analysis, we added the firm's equity return during the quarter as an additional control variable to examine whether the change in earnings is significant over and above the change in equity, since equity returns incorporate earnings changes (e.g. Ball and Brown (1968) and many other studies). The results indicate that changes in profitability are still significant in explaining changes in CDS premia after controlling for equity returns. Thus, earnings include relevant information for the pricing of CDS premia over and above the information contained in equity returns.

Similar to the findings in Table 2, the coefficients on the interactive terms with DEL_INT, DEL_S\&P and DEL_SDRET indicate weaker effects on the five- and tenyear CDS premium changes by comparison to the one-year premium. Note further that the changes in debt ratings do not have significant associations with CDS premium changes ( $\mathrm{p}=0.566$ for the one-year CDS, two-tailed), possibly because ratings do not change significantly over the quarter ${ }^{17}$, or even when they do, the information contained in earnings and leverage changes subsume the information contained in credit rating changes.

Hypothesis H3, regarding short-window changes in CDS premia around preliminary earnings announcements, is tested in Table 4 . The window is the three days centered on the preliminary earnings announcement or, if there are no CDS data during this three-day period, the window is extended up to a maximum of 10 days surrounding the preliminary earnings announcement. Panel A of Table 4 regresses the percentage

\footnotetext{
${ }^{17}$ For close to $90 \%$ of the observations there is no change in rating. When we drop the change in rating from the analysis we obtain similar results.
} 
change of the CDS premium during the short window on the rank of the standardized unexpected earnings (RSUE), where SUE is estimated as earnings for quarter $t$ minus earnings for quarter t-4 less a drift term, scaled by the standard deviation of earnings surprises in the previous eight quarters. The drift in earnings changes is also estimated based on the previous eight quarters. The SUE is ranked into deciles (from 0 , the lowest, to 9 , the highest), and RSUE is the decile rank scaled by nine, minus $0.5 .{ }^{18}$ Consistent with H3, there is a significant inverse relation between the ranked earnings surprise and the changes in the CDS premium over this short window for default swaps with a maturity of one year ( $p=0.000$, two-tailed). Similar to the findings above, the coefficients on the interactive terms for RSUE and CDS maturities of five and ten years show a weakening association between profitability and CDS premium changes; the changes in five-year (ten-year) CDS premia and RSUE are inversely related at the two-tailed significance level of $0.079(0.121)$. Thus, Panel A of Table 4 shows that there is a significant negative association between earnings surprises and CDS premia changes in the short window around the preliminary earnings announcement, indicating that favorable earnings news is interpreted in the CDS market as a signal of reduced likelihood of default. In addition, the negative association is weaker for longer CDS maturities, likely because quarterly earnings surprises have weaker associations with long-term probabilities of default.

(Insert Table 4 about here)

Panel B of Table 4 shows the regression results controlling for the cumulative return on the firm's equity during the preliminary announcement window. The negative and significant association between earnings surprises and changes in one-year CDS

\footnotetext{
${ }^{18}$ Again, the ranking of the earnings surprise is with reference to all firms in Compustat.
} 
premia remains robust, indicating that earnings conveys information about the firm's short-term credit risk beyond the earnings information contained in equity returns. In contrast, the relation between five-year CDS premium and the earnings surprise becomes insignificant after controlling for equity returns, suggesting once more that the earnings surprise conveys less long-term credit risk information.

The short-window hypothesis H4 surrounding the SEC filing date is tested in Table 5. The SEC filing date window is defined similarly to that of the preliminary earnings window, namely, three days centered on the SEC filing if CDS premia are available, and up to a maximum of 10 days otherwise. Since the SEC filings include information beyond the preliminary earnings surprise, the relation between the earnings surprise and the change in CDS premia surrounding the filing cannot be signed a priori. ${ }^{19}$ For example, the cash flow-accruals breakdown provided at the filing date may signal a decline (increase) in earnings quality causing investors to require a higher (lower) CDS premium. Therefore, we follow Griffin (2004), Callen et al. (2006) and others and use an unsigned measure of the earnings surprise to evaluate the relation. Specifically, Panel A of Table 5 shows the regression of the absolute value of the change in CDS premia during the short SEC filing window on the absolute value of RSUE (ABSSUE) ${ }^{20}$ The estimated coefficient on the absolute value of the rank of earnings surprise is positive and significant ( $\mathrm{p}=0.078$, two-tailed) for the one-year maturity, indicating that the greater the earnings surprise (in absolute value) the more informative are the SEC filings to market

\footnotetext{
${ }^{19}$ Although the earnings surprise is already known from the preliminary earnings announcement, the interpretation of the earnings surprise may change given the additional information contained in the financial reports. The results are unchanged even when we control for firms that do not provide preliminary earnings and for firms that have different financial statement earnings than their preliminary earnings.

${ }^{20}$ Recall that RSUE ranges from -0.5 to 0.5 , where -0.5 (0.5) indicates the most negative (positive) earnings surprise.
} 
participants when assessing the short-term default risk of the firm. Similar to the finding described above, the association between the absolute value of the earnings surprise and the absolute value of the change in CDS premium around the SEC filing is weaker and not significantly different from zero for default swaps with medium or long-term maturities.

(Insert Table 5 about here)

Panels B of Table 5 shows that the association between the absolute value of the earnings surprise and the change in CDS premium around the SEC filing remains positive and statistically significant ( $p=0.068$, two-tailed) for the one-year CDS after controlling for the absolute value of the equity return in that short window, and not significantly different from zero for longer CDS maturities.

Panels A and B of Table 6 test Hypothesis H5 regarding the impact of accruals and cash flows on changes in CDS premia around SEC filing dates, respectively. ${ }^{21}$ Callen et al (2006) show that the volatility of unexpected stock returns is associated with net operating cash flows and accruals news, and that these two components of earnings are also associated with risk changes around SEC filings. Given that accruals are associated with changes in risk, we examine in Panel A whether the signed CDS premium is positively associated with the level of accruals. The results reveal that the association of the one-year CDS premium changes with accruals is not significantly different from zero, indicating that these two components are likely unimportant for reinterpreting the firm's default risk, beyond the information contained in earnings. However, somewhat surprisingly, the reported tests at the bottom of the panel show that accruals and changes

\footnotetext{
${ }^{21}$ We conduct separate analyses for accruals and cash flows because the correlation between accruals and cash flows exceeds 0.9 .
} 
in ten-year maturity (five-year) CDS premia are positively and significantly (insignificantly) associated, suggesting that high-accrual earnings are interpreted by the market as indicators of greater long-term default risk, perhaps because accruals indicate investments in net operating assets that can be used to postpone short-term default, but not long-term default.

Panel B show the cash flow regression results. Although the incremental coefficients are not significantly different from zero, again we find that the overall coefficient on the ten-year CDS contract is negative and significant indicating that the higher the cash component of earnings the lower is the long-run risk of default, possibly because higher cash flows signal higher quality earnings and lower long-term credit risk to the CDS market.

Overall, the results are consistent with $\mathrm{H} 5$ with respect to long-term maturities but not medium or short-term maturities. Indeed, the hypothesized relation between maturity and the impact of cash flow/accruals on CDS premia is rejected by the data.

In order to test the robustness of our results, we undertook the following (untabulated) analyses:

1. In the changes regression of Table 3 , we include the cumulative return on the stock during the period as an independent variable. We further include earnings levels as well earnings changes during the quarter. The results remain qualitatively unchanged.

2. We include a dummy variable in the short-window regressions around the preliminary and SEC filing dates for firms that reported net operating cash flows in their preliminary earnings announcements. The main results for these short- 
term windows are qualitatively the same after the inclusion of this dummy variable.

3. We also test the association of CDS premium changes around the SEC filings with changes in leverage reported in the SEC filings. Our results did not show any significant associations, possibly because changes in leverage that significantly affect the firm's default risk are disseminated earlier to the market in the period between the SEC filing dates of the previous and the current quarter through other disclosure media.

4. We replaced accrual and cash flow earnings levels with quarterly changes in accrual and cash flow earnings and obtained results similar to those of Table 6.

\section{Conclusion}

This study evaluates the impact of earnings on short- and long-window changes in firm credit risk, as captured by Credit Default Swaps (CDS) with one-, five- and ten-year maturities. Using levels, quarterly changes and short-window event study methodologies, we find that earnings levels (changes) are significantly and negatively correlated with the level of (changes in) one-year CDS premia even after controlling for equity returns. In contrast, earnings information is not significantly correlated with medium and long term CDS maturities after controlling for equity returns. These results suggest that positive (negative) earnings signals convey favorable (unfavorable) information primarily about short-term default risk. Our empirical results are also consistent with the implications of structural and hybrid models regarding the determinants of CDS pricing. In particular, we

find that CDS premia are increasing in (changes in) leverage and asset volatilities, and 
decreasing in (changes in) the interest rate, and asset values. Although the firm's credit rating is significantly and negatively correlated with CDS premia in the levels analysis, the relationship is insignificant in the changes analysis, possibly because credit ratings are sticky.

We also find that absolute earnings surprises are significantly correlated with oneyear CDS premia changes in the short window surrounding SEC filing date, suggesting that financial statement information at the SEC filing revises the information about shortterm credit risk contained in preliminary earnings. We further find that short-window one-year and 5-year CDS premia changes around the SEC filing date are not significantly related to the accrual/cash flow (changes) breakdown but, surprisingly, short-window 10year CDS premia changes are positively related to accruals (changes) and negatively related to cash flows (changes). These results suggest that the quality of earnings as captured by the accrual/cash flow breakdown provides information about long-term credit risk but not short term credit risk, perhaps because accruals indicate investments in net operating assets that can be used to postpone short-term default, but not long-term default. 


\section{References}

Abid, F. and N. Naifar. 2005. "The Determinants of Credit Default Swap Rates: An Explanatory Study” Working Paper, May, University of Sfax, Tunisia

Aunon-Nerin, D., D. Cossin, T. Hricko and Z. Huang. 2002. "Exploring for the Determinants of Credit Risk in Credit Default Swap Transaction Data: Is Fixed-Income Markets Information Sufficient to Evaluate Credit risk?” Research Paper No. 65, December, FAME, Geneva, Switzerland.

Ball, R. and P. Brown. 1968. "An Empirical Evaluation of Accounting Income Numbers," Journal of Accounting Research 6: 159-178.

Black, F. and J.C. Cox. 1976. "Valuing Corporate Securities: Some Effects of Bond Indenture Provisions," Journal of Finance 31: 351-367.

Blanco, R., S. Brennan and I. W. Marsh. 2005. "An Empirical Analysis of the Dynamic Relation Between Investment-Grade Bonds and Credit Default Swaps," Journal of Finance 60: 2255-2281.

Callen, J.L., J. Livnat and D. Segal. 2006. “The Value Relevance and Information Environment of SEC Filings: A Variance Decomposition Analysis,” Accounting Review 81:1017-1043.

Chan-Lau, J.A. 2006. "Is Systematic Default Risk Priced in Equity returns? A CrossSectional Analysis Using Credit Derivatives,” IMF Working Paper, June.

Collin-Dufresne, P. and R.S. Goldstein. 2001. "Do Credit Spreads Reflect Stationary Leverage Ratios?," Journal of Finance 56: 1929-1957.

Collin-Dufresne, P., R.S. Goldstein, and S. Martin. 2001. "The Determinants of Credit Spread Changes,” Journal of Finance 56: 2177-2207.

Cossin, D. and T. Hricko. 2001. "Exploring for the Determinants of Credit Risk in Credit Default Swap Transaction Data,” Working Paper, May, HEC, University of Lausanne.

Das, S. R. 1995. “Credit Risk Derivatives,” The Journal of Derivatives 2: 7-23.

Das, S. R. and R. Sundaram. 1998. "A Direct Approach to Arbitrage-free Pricing of Credit Derivatives,” NBER working paper no. 6635.

Dichev, I.D. and J.D. Piotroski. 2001. "The Long-Run Stock Returns Following Bond Ratings Changes," Journal of Finance 56: 183-203. 
Duffie, D. and D. Lando. 2001. "Term Structures of Credit Spreads with Incomplete Accounting Information,” Econometrica 69: 633-644.

Elton, E. J., M. J. Gruber, D. Agrawal and C. Mann. 2001. "Explaining the Rate of Spread on Corporate Bonds," Journal of Finance 56: 247-277.

Eom, Y. H., J. Helwege, and J. Huang. 2004, "Structural Models of Corporate Bond Pricing: An Empirical Analysis,” Review of Financial Studies 17: 499—544.

Ericsson, J., K. Jacobs and R. Oviedo. 2005. "The Determinants of Credit Default Swap Premia,” Working Paper, January, Faculty of Management, University of McGill.

Griffin, P. 2003. "Got Information? Investor response to form 10-K and form 10-Q EDGAR filings,” Review of Accounting Studies 8: 433-460.

Houweling, P. and T. Vorst. 2005. "Pricing Default Swaps: Empirical Evidence," Journal of International Money and Finance 24: 1200-1225.

Hull, J., M. Predescu and A. White. 2004. "Relationship Between Credit Default Swap Spreads, Bond Yields, and Credit Rating Announcements," Journal of Banking and Finance 28: 2789-2811

Hull, J. and A. White. 2000a. "Valuing Credit Default Swaps I: No Counterparty Default Risk," Journal of Derivatives 8: 29—40.

Hull, J. and A. White. 2000b. "Valuing Credit Default Swaps II: Including Counterparty Default Risk,” Journal of Derivatives 8: 29—40.

Jorion P. and G. Zhang. 2005. Nonlinear Effects of Bond Rate Changes,” Working Paper, March, University of California at Irvine.

Jorion P. and G. Zhang. 2006. "Intra-industry Credit Contagion: Evidence from The Credit Default Swap and Stock Markets,” Working Paper, February, University of California at Irvine.

Leland, H. E. and K.B. Toft. 1996. "Optimal Capital Structure, Endogenous Bankruptcy, and the Term Structure Of Credit Spreads," Journal of Finance 51: 987-1019.

Longstaff, F. A. and E.S. Schwartz. 1995. "A Simple Approach to Valuing Risky Fixed and Floating Rate Debt," Journal of Finance 50: 789-819.

Longstaff, F. A., S. Mithal and E. Neis. 2005. "Corporate Yield Spreads: Default Risk or Liquidity? New Evidence From The Credit Default Swap Market," Journal of Finance 60: 2213-2253. 
Merton, R. C. 1974. "On the Pricing of Corporate Debt: The Risk Structure of Interest Rates,” Journal of Finance 29: 449-470.

Minton, B.A., R. Stultz, and R. Williamson. 2006. How Much Do Banks Use Credit Derivatives to Reduce Risk,” Working Paper, The Ohio State University.

Pena, J.I. and S. Forte. 2006. "Credit Spreads: Theory and Evidence about the Information Content of Stocks, Bonds and CDSs," Working Paper Departmento de Economia, Universidad Carlos III de Madrid.

Vassalou, M. and Y. Xing. 2003. "Equity Returns Following Changes in Default Risk,” Working Paper Columbia University.

Zhu, H. 2004. "An Empirical Comparison of Credit Spreads between the Bond Market and the Credit Default Swap Market,” Working Paper, BIS. 
$\underline{\text { Table } 1 \text { - Descriptive Statistics }}$

\begin{tabular}{|l|c|c|c|c|c|c|c|c|}
\hline & N & MEAN & SD & MIN & P25 & MEDIAN & P75 & MAX \\
\hline MV & 4143 & 14,366 & 28,568 & 42 & 3,030 & 5,980 & 13,706 & 296,073 \\
CDS_PRL & 3421 & -0.002 & 0.108 & -0.356 & -0.031 & 0.000 & 0.017 & 0.545 \\
CDS_FIL & 3328 & 0.005 & 0.089 & -0.332 & -0.019 & 0.000 & 0.024 & 0.405 \\
CDS_QTR & 2629 & -0.063 & 0.274 & -0.634 & -0.225 & -0.080 & 0.071 & 0.991 \\
CDS_PRM & 3700 & 3.990 & 0.967 & 2.132 & 3.302 & 3.855 & 4.529 & 6.811 \\
ROA & 4138 & 0.013 & 0.017 & -0.058 & 0.005 & 0.012 & 0.021 & 0.062 \\
DEL_ROA & 4138 & 0.001 & 0.014 & -0.060 & -0.003 & 0.001 & 0.005 & 0.061 \\
LEV & 4141 & 0.302 & 0.159 & 0.015 & 0.188 & 0.280 & 0.404 & 0.740 \\
DEL_LEV & 4141 & 0.002 & 0.033 & -0.085 & -0.010 & 0.000 & 0.007 & 0.182 \\
ACC & 4011 & -0.025 & 0.043 & -0.171 & -0.038 & -0.015 & -0.004 & 0.082 \\
OCF & 4014 & 0.037 & 0.046 & -0.062 & 0.013 & 0.027 & 0.051 & 0.199 \\
DOCF & 4141 & 0.374 & 0.484 & 0.000 & 0.000 & 0.000 & 1.000 & 1.000 \\
RATE & 4037 & 10.378 & 2.683 & 2.000 & 9.000 & 10.000 & 12.000 & 23.000 \\
RSUE & 4143 & 4.916 & 2.794 & 0.000 & 3.000 & 5.000 & 7.000 & 9.000 \\
SD_RET & 4087 & 0.018 & 0.014 & 0.002 & 0.012 & 0.015 & 0.021 & 0.438 \\
INT & 4143 & 1.335 & 0.511 & 0.880 & 0.920 & 1.130 & 1.760 & 2.330 \\
SLOPE & 4143 & 1.985 & 0.534 & 1.000 & 1.520 & 2.280 & 2.510 & 2.590 \\
SP & 4143 & 0.037 & 0.052 & -0.102 & 0.013 & 0.014 & 0.071 & 0.149 \\
\hline
\end{tabular}

This table provides descriptive statistics of the main variables used in the paper. MV is the end of quarter market value of equity. CDS_PRL (CDS_FIL) is the change in the CDS premium in the three-day window centered on the preliminary earnings release date (SEC filing date), computed as the CDS premium on the day of the window divided by the CDS premium on the first day of the window minus 1. CDS_QTR is the change in CDS premium during the quarter computed as the premium on the first day after the SEC filing date of the current period divided by the premium on the first day after the SEC filing date of the previous quarter minus 1 . ROA is the return (net income before extraordinary items) on total assets. DEL_ROA is the change in ROA, computed as ROA for the current quarter minus ROA in the previous quarter. LEV is leverage, computed as total debt scaled by total assets in the previous quarter. DEL_LEV is change in leverage. ACC (OCF) is total accruals (operating cash flows) scaled by total assets in the previous quarter. Total accruals are net income before extraordinary items minus net operating cash flows. DOCF is a dummy variable equal to 1 if the firm discloses cash flow information in the preliminary earnings announcement and zero otherwise. RATE is the S\&P's short term credit rating. RSUE is the rank of the standardized earnings surprise SUE. SUE is calculated from the Compustat quarterly database as preliminary EPS minus expected EPS from a seasonal random walk model with drift, scaled by the standard deviation of the forecast errors of the seasonal random walk model. SUE is estimated for each quarter t, using all observations in quarters $\mathrm{t}-8$ through t-1. SD_RET is the standard deviation of daily returns during the firm's current fiscal quarter. INT is the annualized three month T-Bill rate. SLOPE is the difference between the 10year and 2-year t-bill rates. SP is the returns on the S\&P500 index in the firm's current fiscal quarter. 
Table 2: Levels Regression

\begin{tabular}{|l|c|c|c|}
\hline & CDS_1 & CDS_5 & CDS_10 \\
\hline Constant & $\mathbf{3 . 6 0 0}$ & $\mathbf{0 . 4 9 5}$ & $\mathbf{0 . 7 5 1}$ \\
ROA & $\mathbf{( 0 . 0 0 0 )}$ & $\mathbf{( 0 . 0 0 0 )}$ & $\mathbf{( 0 . 0 0 0 )}$ \\
& $\mathbf{- 1 . 5 7 0}$ & $\mathbf{1 . 3 9 4}$ & $\mathbf{2 . 5 4 0}$ \\
LEV & $\mathbf{( 0 . 0 1 9 )}$ & $\mathbf{( 0 . 0 6 2 )}$ & $\mathbf{( 0 . 0 0 1 )}$ \\
& $\mathbf{0 . 6 6 2}$ & -0.058 & $\mathbf{- 0 . 1 4 8}$ \\
SIZE & $\mathbf{( 0 . 0 0 0 )}$ & $(0.449)$ & $\mathbf{( 0 . 0 6 4 )}$ \\
& $\mathbf{- 0 . 8 8 2}$ & $\mathbf{0 . 0 5 0}$ & $\mathbf{0 . 1 0 2}$ \\
INT & $\mathbf{( 0 . 0 0 0 )}$ & $\mathbf{( 0 . 0 0 0 )}$ & $\mathbf{( 0 . 0 0 0 )}$ \\
& $\mathbf{- 0 . 7 1 0}$ & $\mathbf{0 . 4 7 8}$ & $\mathbf{0 . 5 7 9}$ \\
S\&P & $\mathbf{( 0 . 0 0 0 )}$ & $\mathbf{( 0 . 0 0 0 )}$ & $\mathbf{( 0 . 0 0 0 )}$ \\
& -0.001 & -0.116 & 0.060 \\
SDRET & $(0.994)$ & $(0.580)$ & $(0.796)$ \\
& $\mathbf{4 . 5 0 4}$ & $\mathbf{- 1 . 8 9 1}$ & $\mathbf{- 4 . 2 3 4}$ \\
Observations & $\mathbf{( 0 . 0 0 0 )}$ & $\mathbf{( 0 . 0 2 1 )}$ & $\mathbf{( 0 . 0 0 0 )}$ \\
Number of Firms & & 3660 & \\
R-squared & & 376 & \\
\hline
\end{tabular}

The table shows the results of regressing the CDS premium two days after the SEC filing date on the return on assets (ROA), leverage (LEV), log of market value (SIZE), the risk-free interest rate (INT), the return on the S\&P 500 index during the quarter (S\&P), and the standard deviation of the firm's stock return during the quarter (SDRET). For exact variable definitions see the note to Table 1. We estimate the regression using panel data firm and year fixed effects (suppressed) for all 1, 5 and 10 years CDS premia, as well as for all quarters with available data. We include two dummy variables for the 5- and 10-year CDS contracts and interaction terms between these dummy variables and all continuous variables. The coefficients presented in the CDS_5 and CDS_10 columns are those estimated for the interactive variables. For example, the ROA coefficient in the CDS_5 column is the difference between the coefficient on ROA for the 5-year CDS contract and the 1-year CDS contract. The ROA coefficient for the 5-year CDS contract is the sum of the coefficients on ROA in the CDS_1 and CDS_5 columns. To avoid potential multicollinearity and to enhance the interpretation of the interaction terms, all continuous independent variables are demeaned. The p-values of the coefficients are in parentheses. The significant coefficients are bolded.

Earnings and Leverage Coefficient Estimates for 5- and 10-year CDS Maturities

\begin{tabular}{|l|c|c|c|c|}
\hline & \multicolumn{2}{|c|}{ 5-Yaer CDS } & \multicolumn{2}{c|}{ 10-Year CDS } \\
\hline Variable & Coefficient & Significance & Coefficient & Significance \\
\hline ROA & -0.176 & 0.765 & 0.969 & 0.124 \\
\hline Leverage & $\mathbf{0 . 6 0 4}$ & $\mathbf{0 . 0 0 0}$ & $\mathbf{0 . 5 1 4}$ & $\mathbf{0 . 0 0 0}$ \\
\hline
\end{tabular}


Table 3: Changes in Quarterly CDS Premia

\begin{tabular}{|l|c|c|c|}
\hline & CDS_1 & CDS_5 & CDS_10 \\
\hline Constant & $\mathbf{- 0 . 0 3 8}$ & $\mathbf{0 . 0 5 5}$ & $\mathbf{0 . 1 0 1}$ \\
& $\mathbf{( 0 . 0 0 6 )}$ & $\mathbf{( 0 . 0 0 0 )}$ & $\mathbf{( 0 . 0 0 0 )}$ \\
DEL_ROA & $\mathbf{- 2 . 6 1 3}$ & 1.187 & $\mathbf{1 . 8 8 7}$ \\
& $\mathbf{( 0 . 0 0 0 )}$ & $(0.145)$ & $\mathbf{( 0 . 0 2 9 )}$ \\
DEL_LEV & -0.255 & 0.589 & $\mathbf{0 . 8 0 2}$ \\
& $(0.453)$ & $(0.133)$ & $\mathbf{( 0 . 0 5 3 )}$ \\
DEL_INT & $\mathbf{- 0 . 2 2 2}$ & 0.073 & -0.003 \\
& $\mathbf{( 0 . 0 0 2 )}$ & $(0.399)$ & $(0.972)$ \\
DEL_S\&P & $\mathbf{- 0 . 4 9 2}$ & $\mathbf{0 . 0 8 2}$ & $\mathbf{0 . 1 0 1}$ \\
& $\mathbf{( 0 . 0 0 0 )}$ & $\mathbf{( 0 . 0 9 7}$ & $\mathbf{( 0 . 0 5 7 )}$ \\
DEL_SDRET & $\mathbf{0 . 6 5 9}$ & $\mathbf{- 0 . 3 8 6}$ & -0.210 \\
& $\mathbf{( 0 . 0 0 0 )}$ & $\mathbf{( 0 . 0 1 2 )}$ & $(0.227)$ \\
DEL_RATE & $\mathbf{3 . 9 4 4}$ & -0.956 & -0.431 \\
& $\mathbf{( 0 . 0 5 9 )}$ & $(0.667)$ & $(0.847)$ \\
& -0.011 & -0.017 & -0.017 \\
Observations & $(0.566)$ & $(0.590)$ & $(0.602)$ \\
Number of firms & & 2603 & \\
R-squared & & 340 & \\
\hline
\end{tabular}

The table shows the regression results of the quarterly change in the CDS premium on the change in ROA (DEL_ROA), change in leverage (DEL_LEV), change in log market value of equity (DEL_MV), change in the risk free interest rate (DEL_INT), change in the return on the S\&P500 index (DEL_S\&P), computed as the return on S\&P 500 in the current quarter minus the return on the S\&P 500 index in the previous quarter, change in the standard deviation of the firm's stock return (DEL_SDRET) and the change in the firm's S\&P credit rating (DEL_RATE). The dependent variable is computed as the premium on the first day after the filing date of the current period financial statements divided by the premium on the first day after the filing date of the previous quarter minus 1 . For exact variable definitions see the note to Table 1 . We estimate the regression using panel data firm and year fixed effects (suppressed) for all 1, 5 and 10 years CDS premia, as well as for all quarters with available data. We include two dummy variables for the 5and 10-year CDS contracts and interaction variables between these dummy variables and all continuous variables. The coefficients presented in the CDS_5 and CDS_10 columns are those obtained on the interactive variables. To avoid potential multicollinearity and to enhance the interpretation of the interaction terms, all continuous independent variables are demeaned. The pvalues of the coefficients are in parentheses. The significant coefficients are in bold.

Tests for change in earnings and change in leverage on the 5- and 10-year CDS Maturities

\begin{tabular}{|l|c|c|c|c|}
\hline & \multicolumn{2}{|c|}{ 5-Year CDS } & \multicolumn{2}{c|}{ 10-Year CDS } \\
\hline Variable & Coefficient & Significance & Coefficient & Significance \\
\hline DEL_ROA & $\mathbf{- 1 . 4 2 6}$ & $\mathbf{0 . 0 0 6}$ & -0.726 & 0.224 \\
\hline DEL_LEV & 0.334 & 0.172 & $\mathbf{0 . 5 4 7}$ & $\mathbf{0 . 0 4 9}$ \\
\hline
\end{tabular}


Table 4: Changes in CDS Premiums around Preliminary Earnings Release Date

Panel A
\begin{tabular}{|l|c|c|c|}
\hline \multicolumn{1}{|c|}{ CDS_1 } & CDS_5 & CDS_10 \\
\hline Constant & -0.004 & 0.002 & 0.004 \\
& $(0.256)$ & $(0.726)$ & $(0.343)$ \\
RSUE & $\mathbf{- 0 . 0 4 4}$ & $\mathbf{0 . 0 2 6}$ & $\mathbf{0 . 0 2 7}$ \\
& $\mathbf{( 0 . 0 0 0 )}$ & $\mathbf{( 0 . 0 6 1 )}$ & $\mathbf{( 0 . 0 7 0 )}$ \\
\hline Observations & & 3,421 & \\
Number of firms & & 375 & \\
R-squared & & 0.006 & \\
\hline
\end{tabular}

Tests of RSUE for the 5- and 10-year CDS:

\begin{tabular}{|l|c|c|c|c|}
\hline & \multicolumn{2}{|c|}{5 -Year CDS } & \multicolumn{2}{c|}{$10-$ Year CDS } \\
\hline Variable & Coefficient & Significance & Coefficient & Significance \\
\hline RSUE & $\mathbf{- 0 . 0 1 8}$ & $\mathbf{0 . 0 7 8}$ & -0.170 & 0.125 \\
\hline
\end{tabular}

\begin{tabular}{|c|c|c|c|}
\hline \multicolumn{4}{|l|}{ Panel B } \\
\hline & CDS_1 & CDS_5 & CDS_10 \\
\hline Constant & $\begin{array}{c}-0.004 \\
(0.281)\end{array}$ & $\begin{array}{c}0.003 \\
(0.594)\end{array}$ & $\begin{array}{c}0.003 \\
(0.533)\end{array}$ \\
\hline RSUE & -0.036 & 0.025 & 0.018 \\
\hline & $(0.006)$ & (0.111) & $(0.287)$ \\
\hline EQ_RET & -0.269 & 0.038 & 0.140 \\
\hline & $(0.002)$ & & $(0.002)$ \\
\hline Observations & \multicolumn{3}{|c|}{2,896} \\
\hline Number of firms & \multicolumn{3}{|c|}{350} \\
\hline R-squared & \multicolumn{3}{|c|}{0.011} \\
\hline
\end{tabular}

Tests of RSUE for the 5- and 10-year CDS:

\begin{tabular}{|l|c|c|c|c|}
\hline & \multicolumn{2}{|c|}{ 5-Year CDS } & \multicolumn{2}{c|}{ 10-Year CDS } \\
\hline Variable & Coefficient & Significance & Coefficient & Significance \\
\hline RSUE & -0.011 & 0.328 & -0.018 & 0.154 \\
\hline
\end{tabular}

This table shows the regression results of the change in CDS premium around the preliminary earnings release date on the earnings surprise alone (Panel A) and on the earnings surprise and equity returns (Panel B). The dependent variable is the change in the CDS premium and it is computed as the CDS premium on the day after the preliminary earnings release date divided by the CDS premium on the day before the preliminary earnings release date minus 1 . RSUE is the rank of the standardized earnings surprise (see exact definition in the notes to Table 1). EQ_RET is the cumulative equity return in the three days centered on the preliminary earnings release date. We estimate the regression using panel data firm and year fixed effects (suppressed) for all 1, 5 and 10 years CDS premia, as well as for all quarters with available data. We include two dummy variables for the 5- and 10-year CDS contracts and the interaction variables between these dummy variables and all continuous variables. The coefficients presented in the CDS_5 and CDS_10 columns are those estimated for the interactive variables. To avoid potential multicollinearity and to enhance the interpretation the interaction terms, all continuous independent variables are demeaned. The p-values of the coefficients are in parentheses. The significant coefficients are in bold. 
Table 5: Changes in CDS Premiums around Financial Statement Filing Date Panel A - Earnings Surprise

\begin{tabular}{|l|c|c|c|}
\hline & CDS_1 & CDS_2 & CDS_3 \\
\hline Constant & $\mathbf{0 . 0 7 0}$ & $-\mathbf{0 . 0 4 4}$ & $\mathbf{- 0 . 0 2 6}$ \\
& $\mathbf{( 0 . 0 0 0 )}$ & $\mathbf{( 0 . 0 0 0 )}$ & $\mathbf{( 0 . 0 0 0 )}$ \\
ABS_SUE & $\mathbf{0 . 0 2 9}$ & -0.018 & $\mathbf{- 0 . 0 5 1}$ \\
& $\mathbf{( 0 . 0 7 8 )}$ & $(0.342)$ & $\mathbf{( 0 . 0 1 3 )}$ \\
\hline Observations & & 3,328 \\
Number of firms & & 372 & \\
R-squared & & 0.083 & \\
\hline
\end{tabular}

Tests for ABS_SUE on the 5- and 10-year CDS:

\begin{tabular}{|l|c|c|c|c|}
\hline & \multicolumn{2}{|c|}{ 5-Year CDS } & \multicolumn{2}{c|}{ 10-Year CDS } \\
\hline Variable & Coefficient & Significance & Coefficient & Significance \\
\hline ABS_SUE & 0.106 & 0.416 & -0.217 & 0.128 \\
\hline
\end{tabular}

Panel B - Earnings Surprise and Equity Returns Analysis

\begin{tabular}{|l|c|c|c|}
\hline & CDS_1 & CDS_2 & CDS_3 \\
\hline Constant & $\mathbf{0 . 0 7 2}$ & $\mathbf{- 0 . 0 4 6}$ & $\mathbf{- 0 . 0 2 4}$ \\
& $\mathbf{( 0 . 0 0 0 )}$ & $\mathbf{( 0 . 0 0 0 )}$ & $\mathbf{( 0 . 0 0 0 )}$ \\
ABS_SUE & $\mathbf{0 . 0 3 3}$ & -0.018 & $\mathbf{- 0 . 0 5 0}$ \\
& $\mathbf{( 0 . 0 6 8 )}$ & $(0.401)$ & $\mathbf{( 0 . 0 2 7 )}$ \\
ABS_RET & 0.141 & 0.080 & 0.045 \\
& $(0.270)$ & $(0.344)$ & $(0.600)$ \\
\hline Observations & \multicolumn{3}{|}{} \\
Number of firms & \multicolumn{3}{|c|}{} \\
R-squared & \multicolumn{3}{|c|}{0.08346} \\
\hline
\end{tabular}

Tests for ABS_SUE on the 5- and 10-year CDS:

\begin{tabular}{|l|c|c|c|c|}
\hline & \multicolumn{2}{|c|}{ 5-Year CDS } & \multicolumn{2}{c|}{ 10-Year CDS } \\
\hline Variable & Coefficient & Significance & Coefficient & Significance \\
\hline ABS_SUE & 0.154 & 0.309 & -0.017 & 0.317 \\
\hline
\end{tabular}

The table analyzes the change in CDS premia around financial statement filing dates. Panel A shows the regression of the change in absolute value of the CDS premia around the financial statement filing date on the absolute value of the earnings surprise only (ABS_SUE). Panel B repeats the analysis including the absolute value of equity returns (ABS_RET) as an independent variable. The absolute value of the change in the CDS premium around the financial statement filing date is computed as the absolute value of the CDS premium on the day after the financial statement filing date divided by the CDS premium on the day before the financial statement filing date minus 1. ABS_SUE is the absolute value SUE (see the definition in the notes to Table 1). ABS_RET is the absolute value of the cumulative equity return in the three days centered on the financial statement filing date. We estimate the regression using panel data firm and year fixed effects (suppressed) for all 1, 5 and 10 years CDS premia, as well as for all quarters with available data. We include two dummy variables for the 5- and 10-year CDS contracts and the interaction variables between these dummy variables and all continuous variables. The coefficients presented in the CDS_5 and CDS_10 columns are those obtained on the interactive variables. To avoid potential multicollinearity and to enhance the interpretation of the interaction terms, all continuous independent variables are demeaned. The p-values of the coefficients are in parentheses. The significant coefficients are in bold. 
Table 6: Accruals/Cash Flow Analysis

Panel A -Accruals Analysis

\begin{tabular}{|l|c|c|c|}
\hline & CDS_1 & CDS_2 & CDS_3 \\
\hline Constant & $\mathbf{0 . 0 0 8}$ & -0.006 & 0.003 \\
ACC & $\mathbf{( 0 . 0 2 8 )}$ & $(0.159)$ & $(0.444)$ \\
& -0.006 & 0.079 & 0.162 \\
Observations & $(0.941)$ & $0.405)$ & $(0.104)$ \\
Number of firms & & 3,233 & \\
R-squared & & 361 & \\
\hline
\end{tabular}

Tests for ACC on the 5- and 10-year CDS:

\begin{tabular}{|l|c|c|c|c|}
\hline & \multicolumn{2}{|c|}{5 -Year CDS } & \multicolumn{2}{c|}{10 -Year CDS } \\
\hline Variable & Coefficient & Significance & Coefficient & Significance \\
\hline ACC & 0.072 & 0.263 & $\mathbf{0 . 1 5 5}$ & $\mathbf{0 . 0 2 8}$ \\
\hline
\end{tabular}

Panel B - Cash Flow Analysis

\begin{tabular}{|l|c|c|c|}
\hline & CDS_1 & CDS_2 & CDS_3 \\
\hline Constant & $\mathbf{0 . 0 0 8}$ & -0.006 & 0.003 \\
OCF & $\mathbf{( 0 . 0 2 3 )}$ & $(0.152)$ & $(0.464)$ \\
& -0.006 & -0.116 & -0.153 \\
Observations & $(0.152)$ & $0.204)$ & $(0.110)$ \\
Number of firms & \multicolumn{3}{|c|}{} \\
R-squared & \multicolumn{3}{|c|}{361} \\
\hline
\end{tabular}

Tests for OCF on the 5- and 10-year CDS:

\begin{tabular}{|l|c|c|c|c|}
\hline & \multicolumn{2}{|c|}{$5-$ Year CDS } & \multicolumn{2}{c|}{$10-$ Year CDS } \\
\hline Variable & Coefficient & Significance & Coefficient & Significance \\
\hline OCF & -0.097 & 0.133 & $\mathbf{- 0 . 1 3 4}$ & $\mathbf{0 . 0 5 2}$ \\
\hline
\end{tabular}

This table examines the effect of accruals and cash flows on the (signed) change in CDS premia around the filing date. ACC (OCF) is total accruals (operating cash flows) scaled by average total assets. The regression methodology and all other variable definitions are the same as in Table 5. 